\title{
Antibacterial and Antioxidant Studies of Green Synthesized Silver Nanoparticles using Azadirachta indica (Neem) Leaf Extract
}

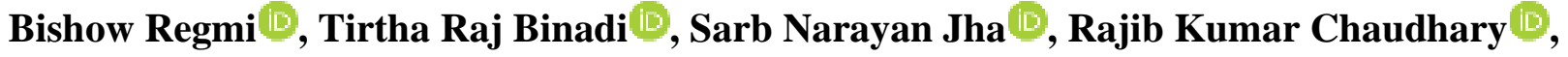 \\ Bhoj Raj Poudel D, Surendra K. Gautam*
}

Department of Chemistry, Tri-Chandra Multiple Campus, Tribhuvan University, Nepal

Article Information
Received: 12 August 2021
Revised version received: 17 September 2021
Accepted: 21 September 2021
Published: 29 September 2021
Cite this article as:
B. Regmi et al. (2021) Int. J. Appl. Sci. Biotechnol. Vol
9(3): 220-226. DOI: $10.3126 /$ ijasbt.v9i3.39069
*Corresponding author
Surendra K. Gautam,
Department of Chemistry, Tri-Chandra Multiple
Campus, Tribhuvan University, Nepal
Email: sgautam2055@yahoo.com /
surendra.gautam@trc.tu.edu.np
Mobile: +977-9841808951

Peer reviewed under authority of IJASBT

(C) 2021 International Journal of Applied Sciences and Biotechnology

\section{OPEN ACCESS}

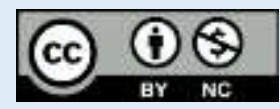

This is an open access article $\&$ it is licensed under a Creative Commons Attribution Non-Commercial 4.0 International (https://creativecommons.org/licenses/by-nc/4.0/)

Keywords: AgNPs, Green synthesis, Antioxidant efficacy, TEM, XRD

\begin{abstract}
Silver nanoparticles (AgNPs) have been synthesized by green synthesis using Azadirachta indica leaf extract as both reducing and stabilizing agent. Synthesis of colloidal AgNPs was monitored by UV- visible spectroscopy. The UVvisible spectrum showed a peak at $455 \mathrm{~nm}$ corresponding to the plasmon absorbance of the silver nanoparticles. Crystallite structure of silver nanoparticles was studied using X-ray diffraction (XRD) analysis which revealed the face-centered cubic structure (FCC) with average particle size of $8.9 \mathrm{~nm}$, calculated using Debye-Scherrer's equation. Transmission electron microscopy (TEM) image revealed the agglomeration of small grain with particle size ranging from 2 to $14 \mathrm{~nm}$. FCC crystalline nature was also evident from selected area electron diffraction (SAED) analysis. High purity of assynthesized AgNPs was analyzed using energy dispersive X-ray (EDX) spectroscopy. Band gap energy was calculated to be $2.7 \mathrm{eV}$ from UV-Visible spectra. 2,2-diphenyl-1-picrylhydrazyl (DPPH) assay was stabilized by AgNPs which reveals its antioxidant efficacy. Well diffusion method showed $7 \mathrm{~mm}$ to $12 \mathrm{~mm}$ zone of inhibition (ZOI) against Gram-positive and Gram-negative bacteria, respectively confirming the antibacterial potential of AgNPs.
\end{abstract}

\section{Introduction}

Nanoparticles possess very high surface to volume ratios. This property of nanoparticles can be utilized in various scientific fields, where high surface is needed (Brijesh et al., 2014; Harikrishna et al., 2009). Nanoparticles have been successfully used in nanochemistry to enhance the immobilization and activity of catalysts, in medical and pharmaceutical nanoengineering for delivery of therapeutic agents, in chronic disease diagnostics, and in sensors. Besides, these nanoparticles have been used in clothing and in the food industry to limit bacterial growth (Harikrishna et al., 2009; Fidel et al., 2010). Because of wide applications in various fields, there are numerous methods for the fabrication of silver nanoparticles. They can be synthesized by several physical, chemical and biological 
methods (Regmi et al., 2019). The synthetic methods used for the preparation of AgNPs often use toxic chemicals as a reducing agent such as $\mathrm{NaBH}_{4}$, citrate, ascorbate etc. (Akl et al., 2012; Florence et al., 2013). Recently, there has been an increased emphasis on the topic of green synthesis of silver nanoparticles (Singh et al., 2010). Green synthetic route for the synthesis of nanoparticles have received much attention to overcome these fallacies. Plants extract synthesis of nanoparticles is gaining importance due to its simplicity and eco-friendly.

AgNPs are synthesized using different plant extracts in literatures such as Dalbergia spinose, Buddleja globose, Argemone Mexicana, etc. In this study, silver nanoparticles are synthesized using plant leaves extract of Azadirachta indica (Neem). A. indica trees are attractive broad-leaved evergreen trees that can grow up to 30 meters in height and have attractive rounded crowns and thick furrowed bark. $A$. indica belongs to Meliaceae family and are native to Nepal, India and South Asian countries (Biu et al., 2009). It is typically grown in tropical and subtropical regions. $A$. indica leaves was found wide scale application in medicine, fertilizers and in industry such as making soaps, etc (Erico et al., 2017).

The historical use of silver as an antibacterial agent made the progression to silver nanoparticles a logical and compelling step. As a naturally antibacterial metal, a silver nanoparticle likely has multiple mechanism of antibacterial activity (Erico et al., 2017); (Rongwei et al., 2009). Silver nanoparticles are effectively applied for the inhibition of Gram-negative and Gram-positive bacteria so it can also be used as killing agent. Besides this, it can also be used in antibiotic resistant strain (Fidel et al., 2010). Similarly, silver nanoparticles have been known to show significant antioxidant efficacy. Antioxidant are those which are capable of inhibiting or delaying the effect of oxidation process due to the atmospheric oxygen and other reactive species (Hyatham et al., 2015).

In this paper, we focus on the preparation of AgNPs by green synthesis method using $A$. indica leaf extract and their antibacterial activity and antioxidant efficacy were studied.

\section{Materials and Methods}

\section{Synthesis of Silver Nanoparticles}

Silver nanoparticles (AgNPs) has been synthesized by using various methods such as chemical synthesis, biosynthesis, and green synthesis (Hyatham et al., 2015; Michael et al., 2001). In this present work, we have chosen green synthesis as the appropriate method. Silver nitrate is used as a source compound for synthesis of silver nanoparticles and green leaves of $A$. indica as reducing agent. Double distilled water was used to prepare the silver nitrate solution and leaf extract.
The fresh leaves of $A$. indica were collected from Janakpur, Nepal. The collected leaves were washed thoroughly and allowed for air dry in room temperature. Exactly, $25 \mathrm{~g}$ of leaves were washed with distilled water thoroughly, dried in room temperature and crushed into fine powder. It was boiled in distilled water for 15 minutes in $80^{\circ} \mathrm{C}$. The solution was filtered using Whatman's filter paper no. 42 and the filtrate was taken as leaves extract to proceed further experiment.

$0.2 \mathrm{M} \mathrm{AgNO}_{3}$ solution was prepared and stored in black bottle to avoid photodegradation. $20 \mathrm{~mL}$ of plant extract was added to the $80 \mathrm{~mL}$ of prepared $\mathrm{AgNO}_{3}$ solution, shaken for $30 \mathrm{~min}$ and incubated in dark for $24 \mathrm{hr}$. Its maximum absorbance was measured using UV- Visible spectroscopy. The mixed solution was heated at $80^{\circ} \mathrm{C}$, filtered and dried to obtain AgNPs. The reaction involved during the process is as follows.

$$
\begin{gathered}
\mathrm{AgNO}_{3} \rightarrow \mathrm{Ag}^{+}+\mathrm{NO}_{3}{ }^{-} \\
\mathrm{Ag}^{+}+\mathrm{e}^{-} \rightarrow \mathrm{Ag}^{0} \\
\text { (Neem extract) }
\end{gathered}
$$

\section{Characterization}

Synthesized AgNPs was characterized using different surface characterization techniques. The crystallite size and structure were determined from XRD patterns obtained using $\mathrm{Cu} \mathrm{k}_{\alpha}$ radiations $(\lambda=1.514 \AA$ ) for $2 \theta$ value ranging from $10^{\circ}$ to $75^{\circ}$ in X-ray diffractometer (Rigaku Ultima IV model). The morphology of the samples was analyzed by transmission electron microscopy (FET Technai ST F20) images and selected area electro diffraction (SAED) pattern. The UV-Vis absorption spectra were obtained from UV-Vis spectrophotometer (ELICO SL 177) and their elemental detection and atomic weight percentage was identified via EDX (JEOL-JSM-6700F) analysis.

\section{Antimicrobial Activity}

The antibacterial activity was observed in two Grampositive bacteria Enterococcus faecalis ATCC 29212 and Bacillus subtilis ATCC 6051 and Gram-negative Enterobacter aerogenes ATCC 29007 in Polytechnic Research Institute of Nepal (PORIN), Kathmandu and stored at $4{ }^{\circ} \mathrm{C}$. The media plates were made of Himedia Nutrient Broth and bacterial lawn cultures were prepared by taking the respective bacteria for the different Petri plates labelled accordingly (Shetty et al., 2017).

$100 \mu \mathrm{L}$ culture broths were spread into nutrient-agar plate (2.5 g/L nutrient media and $2.5 \mathrm{~g} / \mathrm{L}$ agar) and incubated at $37^{\circ} \mathrm{C}$ for $15 \mathrm{~min}$. The agar plate is levelled half with the help of marker then $0.1 \mathrm{gm}$ of silver nanoparticles synthesized using $A$. Indica was placed separately on central part of each half of agar plate carefully and incubated overnight at $37^{\circ} \mathrm{C}$. The antibacterial activity of AgNPs was observed after 24 hr. 


\section{Antioxidant Activity}

The antioxidant activity was determined using 2,2diphenyl-1-picrylhydrazyl (DPPH) method. The free radical scavenging activity of AgNPs was determined using the stable radical DPPH as shown in the Fig. 1.

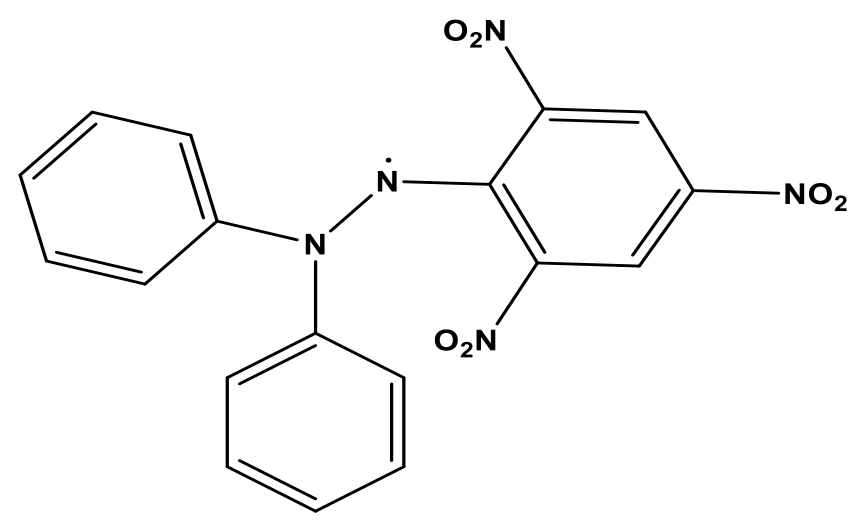

Fig. 1: 2,2-diphenyl-1-picrylhydrazyl (DPPH)

$1 \mathrm{~mL}$ of different concentrations $(10,20,30,40,50,75$, and 100) $\mu \mathrm{g} / \mathrm{mL}$ of AgNPs was mixed with $1 \mathrm{~mL}$ freshly prepared DPPH (by dissolving $0.77 \mathrm{mg}$ of DPPH in $100 \mathrm{~mL}$ of methanol). The solution was incubated at room temperature in the dark for 30 mins. The absorbance was recorded at $517 \mathrm{~nm}$ using UV-Vis spectrophotometer. DPPH was used as a control and methanol was used as a blank solution. The free radical scavenging activity was expressed as the percentage of inhibition which was determined using the following formula.

$\%$ of Scavenging $=\frac{P c-P s}{P c} \times 100$

Where, Pc is the absorbance of control (methanol) and Ps is the absorption of AgNPs (Michael et al., 2001).

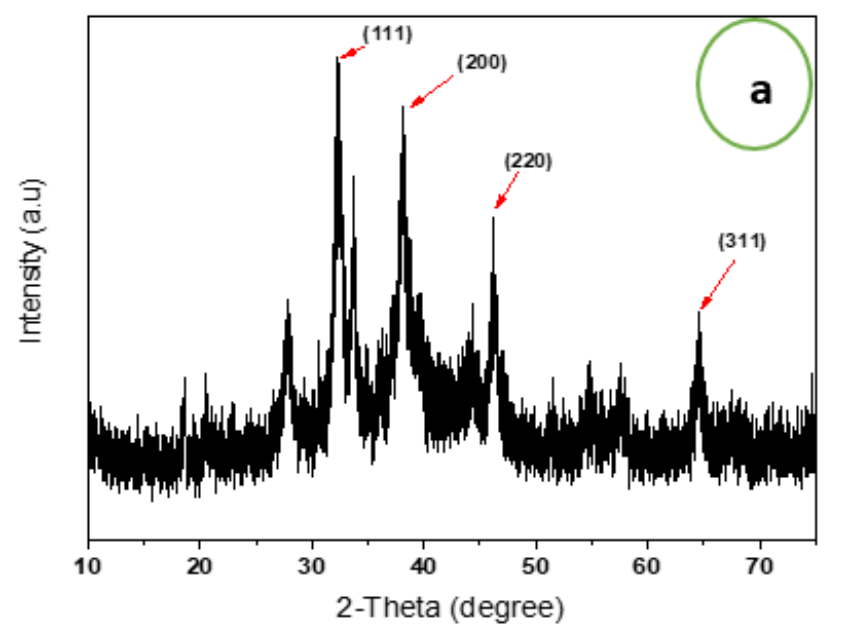

\section{Results and Discussion}

\section{i. $X$-ray diffraction (XRD) studies}

$\mathrm{XRD}$ is a unique technique which provides a wide variety of information of crystalline property of nanoparticles. The average crystalline size can be calculated by Lorentzian profile fitting of most intense XRD diffraction peak using Debye-Scherrer's equation.

Average crystalline size (D) $=\frac{0.94 \lambda}{\beta \cos \theta}$

Where, $\lambda$ is the wave length of $\mathrm{X}$-ray whose value is $0.15406 \AA, \beta$ is full width at half maximum (FWHM) of most intense peak expressed in radians and $\theta$ is Bragg's diffraction angle (Dhungana et al., 2016; Regmi et al., 2019; Gautam et al., 2020).

Figs. 2 (a) and 2 (b) depict the XRD pattern of the AgNPs and corresponding Lorentzian fitting, respectively. The average particle size was found to be $8.9 \mathrm{~nm}$ calculated from Debye-Scherrer's equation. The diffraction peaks observed at $32.4^{\circ}, 46.3^{\circ}, 64.7^{\circ}$, and $77.4^{\circ}$ correspond to (111), (200), (220), and (311) planes of face centered cubic (FCC) crystal structure (JCPDS card 04-0783) (Mehta et al., 2017).

\section{ii. Transmission electron microscopy (TEM) studies}

The typical transmission electron microscopic (TEM) image of well distributed silver nanoparticles is displayed in Fig. 3(a). The agglomeration of nanoparticles may be due to surface forces: van der Waal forces, capillary forces, and electrostatic forces (Muniyappan et al., 2014; Jagtap and Bapat, 2013). The TEM images were processed with the ImageJ software to obtain diameter size distribution of particle. The histogram of particle sizes ranging between 2 $\mathrm{nm}$ to $12 \mathrm{~nm}$ are observed using ImageJ software on TEM image as shown in Fig. 3(b) which is in agreement with the size calculated from XRD data (Gautam et al., 2008).

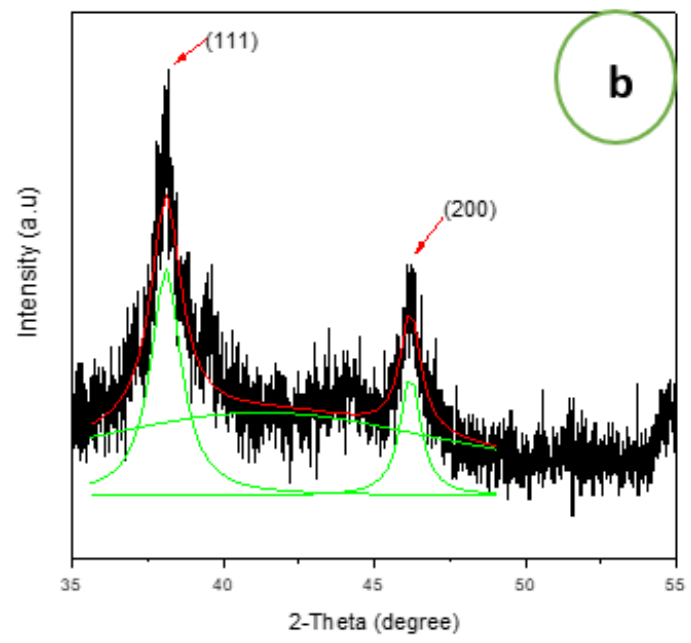

Fig. 2: (a) XRD pattern of AgNPs synthesized using. A. indica leaf extract and (b) corresponding Lorentzian fitting 

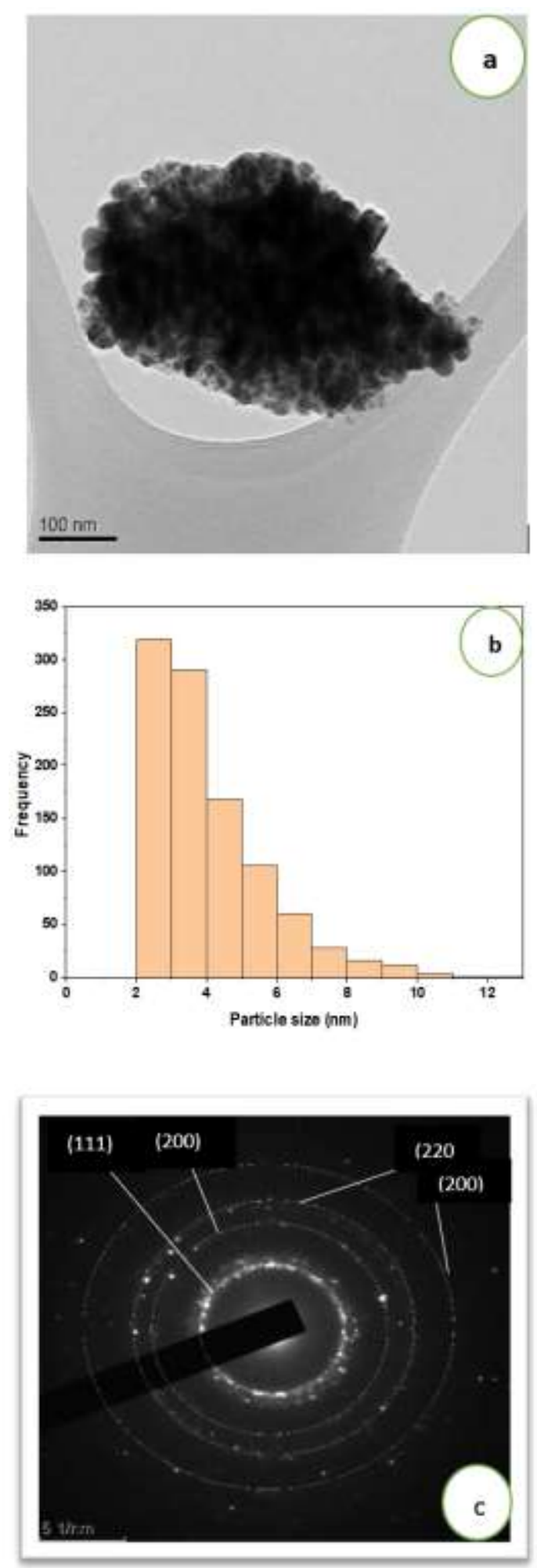

Fig. 3: (a) TEM micrograph of AgNPs, (b) histogram showing particle size of AgNPs and (c) SAED ring pattern of AgNPs synthesized using Azadirachta indica leaf extract

Selected area electron diffraction (SAED) is a crystallographic experimental technique associated with
TEM and basically useful for the phase identification (Prakash et al., 2017). SAED image shown in Fig. 3(c) displays characteristics ring patterns which are consistent with the plane indices (111), (200), (220), and (311) of pure face centered cubic (FCC) silver structure (Harikrishna et al., 2009).

\section{iii. EDX studies}

The purity of Ag nanoparticles was analyzed by EDX pattern as revealed in Fig. 4. Sharp and distinct peak of silver is observed at $3 \mathrm{keV}$ along with other small peaks at $0.1,0.3,0.6,1.5,2.1,2.3$, and $2.7 \mathrm{keV}$. The peaks appeared at $2.7 \mathrm{keV}$ is of chlorine may be due to water present in the leaf extract. Silicon peaks is observed at $1.7 \mathrm{keV}$ which may be contaminated from the borosilicate glass used to store synthesized powdered silver nanoparticles. Peak of oxygen is observed at $0.5 \mathrm{keV}$ may be due to the oxidation of sample with atmosphere (Hyatham et al., 2015). Thus, presence of sharp and intense peaks of $\mathrm{Ag}$ shows the high purity of synthesized nanoparticles.

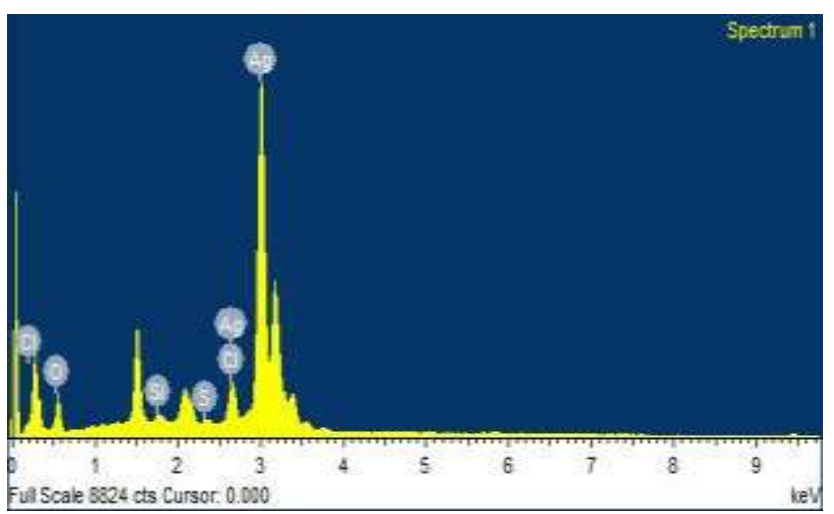

Fig. 4: EDX studies of Ag NPs synthesized using Azadirachta indica leaf extract

\section{iv. $U V$-Visible Studies}

UV-Visible absorption spectroscopy is considered as an efficient technique to monitor the optical property of quantum sized particles. The surface plasmon peak occurred at $355 \mathrm{~nm}$ is due to the presence of ingredients in the leaves for the formation of silver as shown in Figure 5(a). This peak shifted slowly towards the lower wavelength due to blue shift and depends on the particle size and shape. The band corresponds to the absorption by colloidal silver nanoparticles in the region $455 \mathrm{~nm}$ is due to the excitation of surface plasmon vibration (Aziz et al., 2018).

The UV-Vis absorption ability of nanoparticles is related with the band gap energy of that particle and provides a reliable estimate of band gap of any system (Bhujel et al., 2021). The band gap energy is calculated by extrapolating the curve between $(\alpha h v)^{2}$ versus hv to the $\mathrm{x}$-axis as shown in Fig. 5(b) and is found to be $2.7 \mathrm{eV}$. 

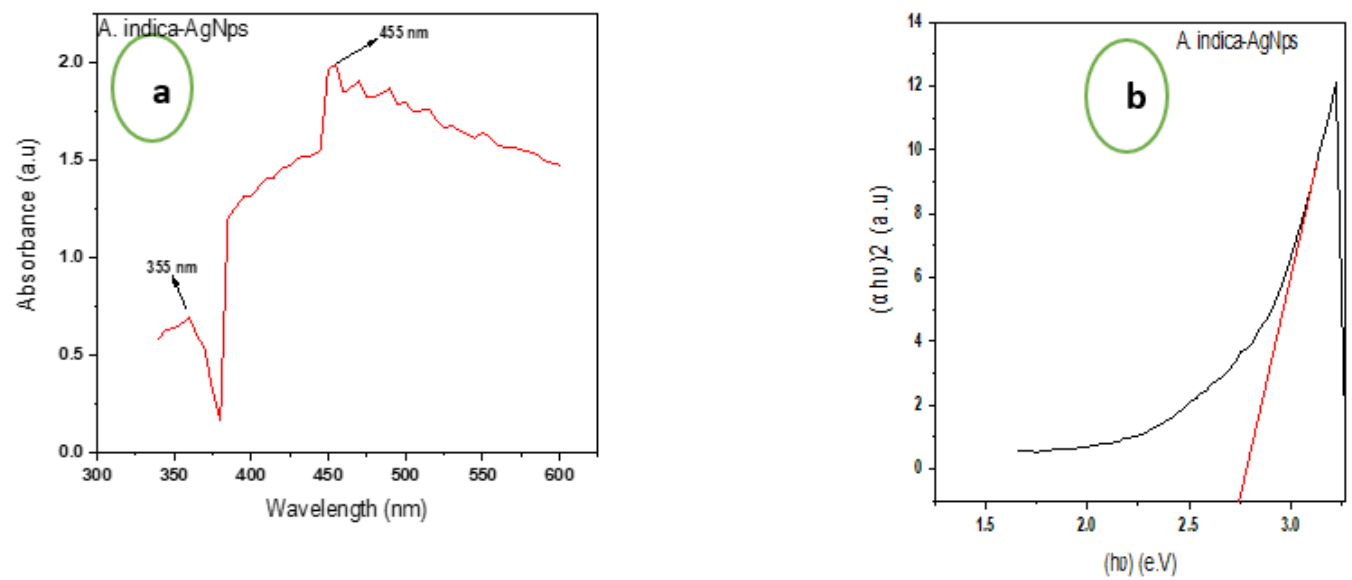

Fig. 5: (a) UV-Visible spectra and (b) Plot of $(\alpha h v)^{2}$ versus photon energy (ho) of Ag NPs

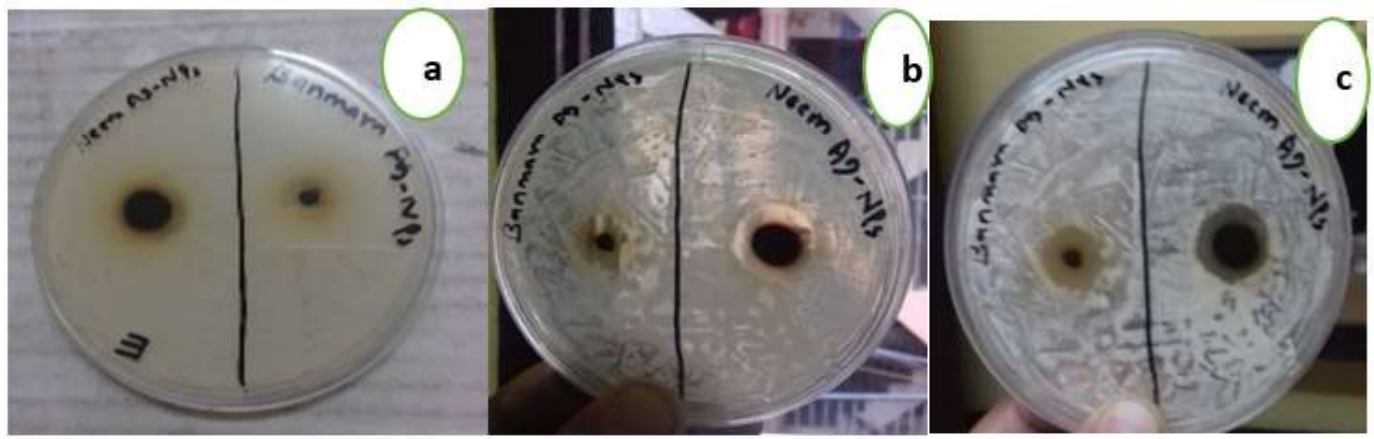

Fig. 6: Antibacterial activity of Ag Nps against bacteria (a) Enterococcus faecalis (b) Bacillus subtilis and (c) Enterococcus aerogenes, respectively.

\section{v. Antibacterial Activities}

The antibacterial activity of green synthesized AgNPs was performed using well diffusion method. Enterococcus faecalis and Bacillus subtilis (Gram-positive bacteria) and Enterococcus aerogenes (Gram-negative) bacterium were cultured in HiMedia broth and incubated at $37^{\circ} \mathrm{C}$ for 24 hours. Then the bacteria were swabbed onto Agar plate using sterile metal swab. $1 \mathrm{mg}$ of AgNPs powder was loaded into the agar plate by making $1 \mathrm{~mm}$ well at the center of the plate. The plate is incubated for $24 \mathrm{hr}$ and the zone of inhibition (ZOI) was measured. Enterococcus faecalis and Bacillus subtilis showed zone of inhibition (ZOI) of $12 \mathrm{~mm}$ and $7 \mathrm{~mm}$, respectively while the Gram-negative bacteria Enterococcus aerogenes observed ZOI of $11 \mathrm{~mm}$ which approves the antibacterial activity of AgNPs (Fig. 6) (Gautam et al., 2021).

Antibacterial effects of AgNPs obeyed a dual action mechanism of antibacterial activity; the bactericidal effects of $\mathrm{Ag}^{+}$and membrane disrupting effects of the polymer subunits. The AgNPs synthesized via green route are highly toxic to multidrug resistant bacterial hence has much potential in biomedical applications (Maribel et al., 2009).

\section{vi. Antioxidant Activities}

Antioxidant activity of as-synthesized AgNPs is studied using DPPH assay method. The DPPH radical absorbs at
$517 \mathrm{~nm}$ and antioxidant activity can be determined by monitoring the decrease in this absorbance. The percentage of free radical scavenging activity at different concentration ranging from $5 \mathrm{mM}$ to $9 \mathrm{mM}$ for AgNPs was evaluated. It was found that the efficacy of AgNPs as an antioxidant activity increases with increase in concentration which is displayed in Fig. 7.

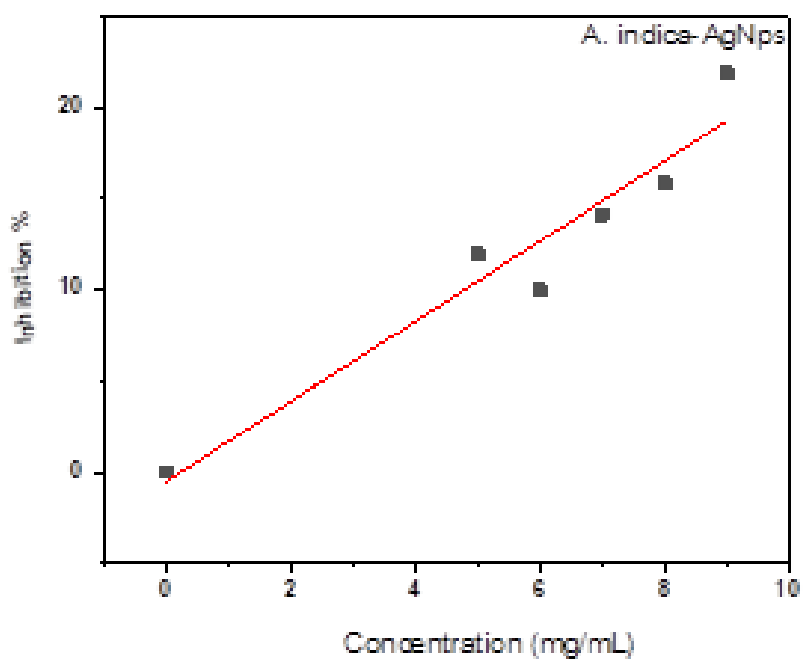

Fig. 7: Graphical representation of antioxidant efficacy of AgNPs assessed using DPPH assay method. 


\section{Conclusion}

The result shows that the substantial amount of AgNPs was synthesized using Azadirachta indica leaf extract acting as both reducing and capping agents. UV-Visible spectra display surface plasmon resonance absorption peak at 455 $\mathrm{nm}$ and band gap calculated as $2.7 \mathrm{eV}$. XRD analysis reveals the face-centered cubic (FCC) structure with average particle size of $8.9 \mathrm{~nm}$. TEM analysis shows the particles ranges from 2 to $12 \mathrm{~nm}$ and SAED verifies FCC crystalline structure of AgNPs. EDX analysis signifies the high purity of synthesized samples. AgNPs shows significant antibacterial activity against Enterococcus faecalis, Bacillus subtilis and Enterococcus aerogenes bacteria. AgNPs possesses substantial antioxidant efficacy and can be used in medical purposes.

\section{Acknowledgements}

We are grateful to Department of Chemistry, Tri-Chandra Campus, Tribhuvan University for laboratory facilities. Authors are greatly indebted to Dr. Laxmi Thapa (PORIN, Kathmandu) for antibacterial test. Thanks to Ms. Indira Pokhrel, Sogang University, S. Korea for XRD, TEM, SAED and EDX measurements.

\section{Conflicts of Interest}

The authors declare no conflicts of interest with present publication.

\section{Funding}

This study was self-financed and no funding was obtained or acquired.

\section{Ethical Approval}

Not required given the nature of the article.

\section{References}

Akl M and Nida MS (2012) Green Synthesis of Silver Nanoparticles by Mulberry Leaves Extract. Nanoscience and Nanotechnology 2(4): $125-128$. $\underline{10.5923 / \mathrm{j} . \mathrm{nn} .20120204 .06}$

Aziz A, Khalid M, Saeed M, Nadeem M and Saleem M (2018) Structural Morphological and Optical Investigation of Silver Nanoparticles Synthesis by Sol-gel Autocombustion Method. Digest Journal of Nanomaterials and Biostructures, 13(3): 679-683.

Bhujel A, Sapkota B, Aryal RL, Poudel BR, Bhattarai S and Gautam SK (2021) Insight of Precursor Concentration, Particle Size and Band Gap of Zirconia Nanoparticles Synthesized by Co-precipitation Method. Bibechana 18: 1-9. DOI: $\underline{10.3126 / \text { bibechana.v18i0.28958 }}$

Birjesh K, Kumari S, Luis C, Alexis D, Javier C, Elisabeth HG, Maria CL and Yolanda A (2014) Pomosynthesis and Biological Activity of Silver Nanoparticles using Passiflora tripartite Fruit Extracts. Advanced Material Letter 11(14): 127-132. DOI: $10.5185 /$ amlett.2015.5697

Biu AA, Yusufu SD and Rabo JS (2009) Phytochemical Screening of Azadirachta indica (Neem) (Meliaceae) in Maiduguri,
Nigeria. Bioscience Research Communication 21(6): 281283.

Dhungana S, Poudel BR and Gautam SK (2016) Synthesis and Characterization of ZnTe Nanoparticles. Nepal Journal of Science and Technology 17(1): 1-3. DOI: 10.3126/njst.v17i1.25054

Erico RC, Noelia B, Tanya P and Gonzalo RS (2017) Green Synthesis of Silver Nanoparticles by using Leaf Extracts from the Endemic Buddleja globose Hope. Green Chemistry Letters and Reviews 8(10): 250-256. DOI: $\underline{10.1080 / 17518253.2017 .1360400}$

Fidel MG, Peggy L, Adriana B, Erasmo O, Nereyda N, Elipido MS, Facundo R, Horacio B and Yossef AG (2010) Synthesis, Characterization and Evaluation of Antimicrobial and Cytotoxic Effect of Silver and Titanium Nanoparticles. Nanomedicine 2(2): 681-688. DOI: $\underline{10.1016 / \text { j.nano.2010.02.001 }}$

Florence O, Afef J, Tatiana K, Vernessa E and Michael C (2013) Green Synthesis of Silver Nanoparticles, their Characterization, Application and Antibacterial Activity. International Journal of Environmental Research and Public Health 10(21): DOI: 10.3390/ijerph10105221

Gautam SK, Baid Y, Thapa Magar P, Binadi TR and Regmi B (2021) Antimicrobial Study of Green Synthesized Silver Nanoparticles (AgNPs) by using Ageratina adenophora and its Characterization. International Journal of Applied Science and Biotechnology 9(2): 128-132. DOI: $\underline{10.3126 / \text { ijasbt.v9i2.37822 }}$

Gautam SK, Pandey D, Upadhyay SN, Anwar S and Lalla NP (2008) Unambiguous Evidence for Wurtzite Phase in Capped CdS Quantum Dots. Solid State Communication 146: 425-427. DOI: $\underline{10.1016 / j . s s c .2008 .03 .020}$

Gautam SK, Sapkota B, Bhujel A and Bhattarai S (2020) Estimation of Particle Size and Band Gap of Zinc Oxide Nanoparticle Synthesized by Chemical Precipitation Method. Journal of Nepal Chemical Society 41: 46-50. DOI: $\underline{10.3126 / \text { jncs.v41i1.30448 }}$

Harikrishna B, Dipak KB, Gobinda PS, Priyanka S, Sankar PD and Ajaya M (2009) Green Synthesis of Silver Nanoparticles using Latex of Jatropha curcas. Colloidal and Surface A. 2(20): DOI: 10.1016/j.colsurfa.2009.02.008

Hyatham MMB (2015) Green Synthesis and Characterization of Silver Nanoparticles using Banana Peel Extract and their Antimicrobial Activity Against Representative Microorganisms. Journal of Radiation Research and Applied Sciences 1(20): 1-11. DOI: $\underline{10.1016 / j \text { jras.2015.01.007 }}$

Jagtap UB and Bapat VA (2013) Green synthesis of silver nanoparticles using Artocarpus heterophyllus Lam. seed extract and its antibacterial activity. Industrial crops and products $\quad 46$ : 132-137. DOI: $\underline{\text { 10.1016/j.indcrop.2013.01.019 }}$

Maribel G, Jean D and Stephen G (2009) Synthesis of Silver Nanoparticles by Chemical Reduction Method and their Antibacterial Activity. International Journal of Chemical 
and Biomolecular Engineering 2(3): 104-110. DOI: $\underline{10.1016 / i j c b .156722 \mathrm{e}}$

Mehta BK, Chhajlani M and Shrevastava BD (2017) Green Synthesis of Silver Nanoparticles and their Characterization by XRD, J Phy: Conf Ser 836: 1-4. DOI: $\underline{10.1088 / 1742-6596 / 836 / 1 / 012025}$

Michael A, Paul DP, Emilios P, Suzanne M and Kevin R (2001) Methods of Testing Antioxidant Activity. The Royal Society of Chemistry 11(23): 183-198. DOI: $\underline{10.1039 / \mathrm{b} 009171 \mathrm{p}}$

Muniyappan N and Nagarajan NS (2014) Green Synthesis of Silver Nanoparticles with Dalbergia spinose Leaves and their Applications in Biological and Catalytic Activities. Process Biochemistry 8(3): 1-33. DOI: 10.1016/j.procbio.2014.03.015

Prakash JD and Samuel PD (2017) Green Synthesis of Silver Nanoparticles by Boucerosis procumbens. International Journal of Applied Sciences and Biotechnology 5(2): $\underline{10.3126 / \text { ijasbt.v5i2 }}$
Regmi A, Bhandari J, Bhattrai S and Gautam SK (2019) Synthesis, Characterization and Antimicrobial Activity of Cuprous Oxide Nanoparticles. Journal of Nepal Chemical Society 40: 5-10. DOI: $10.3126 /$ jncs.v40i0.27271

Rongwei Z, Kyoung M, Wei L and Wong C (2009) Preparation of Highly Conductive Polymer Nanocomposites by Low Temperature Sintering of Silver Nanoparticles. Journal of Material Science 12(5): 2018-2023. DOI: $\underline{10.1039 / \mathrm{b} 921072 \mathrm{e}}$

Shetty P, Souza AD, Poojari S, Narayana J and Rajeeva P (2017) Study of Fermentation Kinetics of Palm Sap for Cocos nucifera. International Journal of Applied Sciences and Biotechnology 5(3): $\quad 375-381 . \quad$ DOI: 10.3126/ijasbt/v5i3.1829

Singh A, Jain D, Upadhyay MK, Khandel N and Verma HN (2010) Green Synthesis of Silver Nanoparticles using Argemone mexicana Extract and Evaluation of their Antimicrobial Activities. Digest Journal of Nanomaterials and Biostructures 7(24): 483-489. 